\title{
Estabilidade Aeróbica de Silagens de Capim-Elefante (Pennisetum purpureum, Schum) Emurchecido e Tratado com Inoculante Microbiano ${ }^{1}$
}

\section{Adriana Guim², Pedro de Andrade ${ }^{3}$, Ruben Pablo Iturrino-Schocken ${ }^{3}$, Gumercindo Loriano Franco $^{4}$, Ana Cláudia Ruggieri ${ }^{5}$, Euclides Braga Malheiros ${ }^{3}$}

\begin{abstract}
RESUMO - Para avaliar o efeito de um inoculante microbiano sobre a estabilidade aeróbica de silagens de capim-elefante (Pennisetum purpureum, Schum) pré-seco, foi conduzido um experimento na UNESP, Campus de Jaboticabal. O capim foi cortado com 96 dias de crescimento, permanecendo sob ação do sol, por aproximadamente 5 horas para o emurchecimento. Foram confeccionados silagens, em barricas plásticas de $200 \mathrm{~L}$ de capacidade, que receberam (CI) ou não (SI) o inoculante no momento da ensilagem. Para o estudo da deterioração aeróbica, na abertura dos silos (T0), cada barrica foi subdividida em três profundidades e as silagens expostas ao ar em um sistema, usado para a determinação de $\mathrm{CO}_{2}$, por 2 (T2), 4 (T4), 6 (T6) e 8 (T8) dias. A silagem da camada superficial não apresentou diferenças no valor de $\mathrm{pH}$ e contagem de leveduras, em relação à da camada intermediária, porém ambas apresentaram valores superiores à camada mais profunda. $\mathrm{O}$ teor de $\mathrm{N}-\mathrm{NH}_{3}$ da camada superior foi menor que o da intermediária e profunda, que não diferiram entre si. A interação significativa entre inóculo e tempo de exposição mostrou que nos primeiros tempos de aeração (T0; T2 e T4) as silagens inoculadas não diferiram das controle em termos de $\mathrm{pH}$, teor de $\mathrm{N}-\mathrm{NH}_{3}$ e contagem de bolores, mas com avanço do tempo (T6 e T8) passaram a apresentar menor valor de $\mathrm{pH}$, menor contagem de fungos e tendência a menor produção de $\mathrm{CO}_{2}$, indicando menor velocidade de deterioração após seis dias de exposição aeróbica.
\end{abstract}

Palavras-chave: capim-elefante, estabilidade aeróbica, inoculação, silagem

\section{Aerobic Stability of Wilted Grass Silages (Pennisetum Purpureum, Schum.) Treated with Microbial Inoculant}

\begin{abstract}
An experiment was carried out at UNESP, Jaboticabal Campus to evaluate the effect of a microbial inoculant on aerobic stability of wilted grass silage (Pennisetum purpureum, Schum). The grass was cut with 96 days of growing, remaining under sun action 5 hours to wilt. Silages were made in plastic silos, $0.2 \mathrm{~m}^{3}$ capacity, that received (CI) or not (SI) inoculant at the ensilage time. For the study of aerobic deterioration, each silo was subdivided in three levels and the silages were exposed in a system, used to evaluate $\mathrm{CO}_{2}$ production, for 2 (T2), 4(T4), 6(T6) and 8(T8) days. Surface silage had higher $\mathrm{pH}$ value, lower $\mathrm{NH}_{3}-\mathrm{N}$ content, and higher yeast count than middle and bottom silages. The significant interaction between inoculation and aeration stage, shown that at earlier stages (T0, T2 and T4) there was no difference between treated and control silages in $\mathrm{pH}, \mathrm{N}-\mathrm{NH}_{3}$ and mold count, but at later stages (T6 and $\mathrm{T} 8$ ), inoculated stages had lower $\mathrm{pH}$ value, mold count and tended to a lower $\mathrm{CO}_{2}$ production, showing a lower deterioration speed after 6 days of aerobic exposure.
\end{abstract}

Key Words: aerobic stability, elephantgrass, inoculation, silage

\section{Introdução}

Forrageiras de clima tropical apresentam contraste entre valor nutritivo e produção por unidade de área, influenciado pelas condições climáticas ou por características da própria planta. É fato bem conhecido que, com a maturação, as plantas, ainda que aumentem a produção de matéria seca, têm o seu valor nutritivo reduzido (Vilela, 1994). O capim- elefante (Pennisetum purpureum, Schum) não constitui exceção, pois há declínio acentuado de seu valor nutritivo com o avanço do crescimento. A ensilagem constitui um dos principais métodos de conservação dessa gramínea, já que sua utilização, na forma de pastejo ou como reserva forrageira para corte, apresenta a mesma seqüência ao longo do ciclo de crescimento com alterações qualitativas e quantitativas da planta, devido às variações climáticas.

\footnotetext{
${ }^{1}$ Parte da tese de doutorado da primeira autora.

2 Professora da Universidade Federal Rural de Pernambuco - R. Dom Manoel de Medeiros, S/N Recife (PE) CEP: $52171-900$. E.mail:muriguim@uol.com.br

3 Professores da UNESP Campus de Jaboticabal (SP).

${ }^{4}$ Professor da Universidade de Brasília (DF).

5 Pesquisadora do Instituto de Zootecnia, Nova Odessa (SP). E.mail:ruggieri@izsp.br
} 
A preservação de nutrientes na ensilagem decorre da fermentação pelos lactobacilos ou outras bactérias produtoras de ácido lático. Para obtenção de uma ação efetiva desses microrganismos, são necessárias quatro condições: 1) material fermentante para permitir o crescimento bacteriano; 2) ausência de $\mathrm{O}_{2}$ no material, para favorecer o crescimento de lactobacilos anaeróbicos; 3) número suficiente de lactobacilos para que sejam rapidamente dominantes sobre outras espécies microbianas e 4) baixa umidade para evitar que os ácidos produzidos se diluam favorecendo uma fermentação butírica (Bughardi et al., 1980).

O teor de matéria seca do capim-elefante é um fator limitante para sua utilização na forma de silagem. A técnica de emurchecimento possibilita o armazenamento de forragens cortadas com baixo teor de matéria seca, em um processo simples, no qual as fermentações indesejáveis são facilmente controladas por meio do aumento da pressão osmótica (Muck, 1990).

Aditivos estimulantes da fermentação durante a ensilagem são usados para aumentar a probabilidade de obtenção de fermentação satisfatória e silagem de alto valor nutritivo com mínimas perdas na ensilagem (Sharp et al., 1994). Por outro lado, na maioria dos estudos com inoculantes foi observada redução na estabilidade aeróbica das silagens inoculadas (Spoelstra, 1994). A presença de $\mathrm{O}_{2}$, pela entrada de ar durante o período de estocagem ou na abertura do silo, favorece o crescimento de microrganismos aeróbicos. Esses microrganismos utilizam vários substratos derivados diretamente da forragem ou indiretamente da fermentação. $\mathrm{O}$ resultado dessa atividade é a perda de nutrientes e conseqüente redução no valor nutritivo da silagem (Honig \& Woolford, 1980). É importante ressaltar que as perdas ocorridas durante a deterioração aeróbica são provocadas pela atividade microbiana, mas essa atividade é limitada, normalmente, por fatores químicos e físicos, como fornecimento de oxigênio e alterações da temperatura (Willians et al., 1994).

Se o período de exposição ao ar for longo, podem ocorrer grandes transformações na composição química das silagens, o que influi adversamente em seu valor nutritivo. Essas alterações ocorrem primeiramente devido às bactérias e leveduras e, subseqüentemente, aos fungos. Inicialmente os componentes solúveis das silagens, carboidratos solúveis, os ácidos orgânicos e os compostos nitrogenados solúveis, agem como substratos para o desenvolvimento desses microrganismos, e as perdas desses nutrientes resultam em correspondente aumento nos conteúdos de fibra em detergente neutro, fibra em detergente ácido e cinzas, e perda de nutrientes digestíveis e energia (McDonald et al., 1991; Pitt \& Shaver, 1990).

As alterações na composição das silagens são acompanhadas pelo aumento do $\mathrm{pH}$, temperatura e nitrogênio amoniacal, embora, neste último, as alterações sejam inconsistentes devido às variáveis perdas por volatilização (McDonald et al., 1991). Nos estágios finais da deterioração, os carboidratos estruturais também podem ser decompostos (Honig \& Woolford, 1980).

A suscetibilidade da silagem à deterioração parece ser governada mais pela população dos fungos do que pela composição química da silagem (Beck e Gross, citados por Woolford, 1990). A respiração dos microrganismos aeróbios pode ser considerada como um dos principais agentes que influenciam a qualidade das silagens. Entretanto, o substrato utilizado para a respiração depende do tipo do microrganismo; por exemplo, as leveduras consomem apenas compostos solúveis (açúcares e produtos da fermentação), enquanto os bolores degradam uma ampla variedade de nutrientes, inclusive carboidratos estruturais e lignina (McDonald et al., 1991).

A presença desses fungos é indesejável, não somente porque quebram o açúcar e o ácido lático pela via normal da respiração, mas também hidrolisam e metabolizam a celulose e outros componentes da parede celular. Além disso, alguns bolores, principalmente as espécies dos gêneros Aspergillus, Fusarium e Penicillum, crescem em silagens onde há penetração de ar e produzem toxinas que são prejudiciais aos animais e ao homem (McDonald et al., 1991; Muck, 1992).

A silagem é uma importante técnica para conservação de forragens e a deterioração aeróbica durante sua utilização é seu principal problema, o que torna essencial a compreensão desse processo. Nesse sentido, o objetivo do trabalho foi avaliar os efeitos de um inoculante microbiano sobre a estabilidade aeróbica de silagens de capim-elefante (Pennisetum purpureum, Schum) pré-seco.

\section{Material e Métodos}

Para o estudo dos efeitos do inoculante microbiano sobre a estabilidade aeróbica de silagens de capim-

R. Bras. Zootec., v.31, n.6, p.2176-2185, 2002 
elefante (Penissetum purpureum, Schum) pré-seco, foi realizado um experimento no setor de Avaliação de Alimentos e Balanço Nutricional da Faculdade de Ciências Agrárias e Veterinárias da Universidade Estadual Paulista- Campus de Jaboticabal. As análises químicas e bromatológicas foram executadas no Laboratório de Nutrição Animal e as análises microbiológicas, no Laboratório de Microbiologia, ambos da mesma Universidade.

O inoculante microbiano utilizado, originalmente denominado de "Effective Microorganisms" (E.M.), é constituído por grupos de microrganismos encontrados na natureza, benéficos ao homem e reproduzidos em meio de cultura fermentante. $\mathrm{O}$ conceito do E.M. foi desenvolvido pelo Professor Teruo Higa, Universidade de Ryukyus, Okinawa, Japão. No Brasil, são produzidos pela Fundação Mokiti Okada e vêm sendo utilizados experimentalmente nos cultivos de hortaliças, cereais, frutas e flores sem defensivos químicos e ainda não se encontra comercialmente disponível no mercado.

Para permitir que esses microrganismos atuem com eficiência, é necessária a presença de matéria orgânica no solo. Tem-se documentado cientificamente que, por intermédio de reações de fermentação, estes microrganismos produzem ácidos orgânicos, hormônios vegetais (giberilinas, auxinas e citoquininas), além de vitaminas, antibióticos e polissacarídeos (Higa, 1992).

A fermentação da matéria orgânica existente no solo resulta em proliferação de vários outros grupos de microrganismos, produção de gomos bacterianos e crescimento de fungos e actinomicetos que levam à estruturação física do solo, agregando melhor as partículas minerais do solo, eliminando a compactação, aumentando a porosidade, infiltração de água, água disponível e profundidade de enraizamento. Como conseqüência deste fato, pode ocorrer redução da erosão e frequiência de irrigação (Tokeshi et al., 1994). Outras fontes de matéria orgânica, como as de origem animal, também são fermentadas pelos microrganismos do E.M., resultando em substâncias úteis ao crescimento das plantas e promovendo o equilíbrio do solo.

Trata-se de um líquido com pH 3,2 constituído por espécies de microrganismos incluindo populações predominantes de bactérias ácido láticas (Lactobacillus e Pediococcus) e leveduras (Sacharomyces) e número menor de bactéria fotossintética e actinomicetos. Todas são compatíveis umas com as outras e podem coexistir em cultura líquida (Higa \& Parr, 1994). As leveduras apresentam-se em concentração de $2 \times 10^{6}$ Unidades Formadoras de Colônia (UFC)/mL da suspensão e as bactérias produtoras de ácido lático em 1 X $10^{5} \mathrm{UFC} / \mathrm{mL}$.

O capim-elefante foi proveniente de uma capineira de 0,5 ha, previamente roçada para uniformização. Em 08 de maio de 1996 (outono), quando a gramínea atingiu 96 dias de crescimento, com 1,70 m de altura foi efetuado o corte do capim, a $15 \mathrm{~cm}$ do solo com uma colhedora de forragem, permanecendo sob ação do sol, em um terreiro, por aproximadamente cinco horas para o emurchecimento.

Foram confeccionadas silagens que receberam (CI) ou não (SI) o inóculo no momento da ensilagem. Para a confecção das silagens inoculadas, a forragem emurchecida foi dividida em porções previamente pesadas, sendo espalhadas no terreiro formando camadas de 10 a $15 \mathrm{~cm}$ onde foram regadas com E.M. diluído em água na proporção de 1:50 (1 de E.M. para 50 de água), utilizando-se $45 \mathrm{~mL}$ de EM ( $2250 \mathrm{~mL}$ da solução) para $100 \mathrm{~kg}$ de capim. As silagens não inoculadas receberam a mesma quantidade de água utilizada para as silagens inoculadas. Foram recolhidas e congeladas amostras de $0,5 \mathrm{~kg}$ da forragem fresca e murcha antes da ensilagem, para posterior análises de poder tampão (PT); conteúdo de matéria seca (MS) e proteína (PB); e teor de carboidratos solúveis (CS), segundo as metodologias descritas por Playne \& McDonald (1966), Silva (1981) e Johnson et al.(1966), respectivamente. As características químicas da forragem fresca e emurchecida, no momento da ensilagem, estão apresentadas na Tabela 1 .

A forragem foi ensilada em seis barricas plásticas de $200 \mathrm{~L}$ (48cm de diâmetro x $97 \mathrm{~cm}$ de altura) de capacidade (três com e três sem o inoculante), que permaneceram lacradas por 70 dias.

$\mathrm{Na}$ abertura dos silos experimentais, cada barrica foi subdividida em três profundidades: superficial $(0-35 \mathrm{~cm})$, intermediária $(35-65 \mathrm{~cm})$ e fundo $(65-97$ $\mathrm{cm})$. As silagens foram expostas ao ar em um sistema usado para a determinação de $\mathrm{CO}_{2}$, descrito por Ashbell et al.(1991), na abertura (T0), aos 2 (T2), 4 (T4), 6 (T6) e 8 (T8) dias.

O sistema era constituído por garrafas de polietileno (PET) de dois litros de capacidade. Para o preparo de uma unidade foram necessárias duas garrafas. A parte superior de uma garrafa, correspondendo ao volume de um litro, foi seccionada, sendo usada como a parte superior do sistema e a base original da garrafa usada como tampa do siste-

\section{R. Bras. Zootec., v.31, n.6, p.2176-2185, 2002}


Tabela 1 - Composição químico-bromatológica da forragem fresca (F) e murcha (M) no momento da ensilagem (T0), sem (SI) e com (CI) inoculante microbiano

Table 1 - Chemical composition of fresh (F) and wilted (W) forage at ensilage (TO), with (WI) or without (WO) microbial inoculant

\begin{tabular}{|c|c|c|c|c|}
\hline $\begin{array}{l}\text { Forragem } \\
\text { Forage }\end{array}$ & $\begin{array}{c}\mathrm{PT}^{1}(\text { eq } \mathrm{mg} \text { de } \mathrm{HCl} / 100 \mathrm{~g} \mathrm{MS}) \\
B C^{l}(e q m g \text { de } \mathrm{HCl} / 100 \mathrm{~g} \mathrm{DM})\end{array}$ & $\begin{array}{l}\mathrm{CS}^{2}(\% \text { na } \mathrm{MS}) \\
W S C^{2}(\% \text { of } D M)\end{array}$ & $\begin{array}{l}\mathrm{MS}^{3} \text { original } \\
\text { original } D M^{3}\end{array}$ & $\begin{array}{l}\mathrm{PB}^{4}(\% \text { na } \mathrm{MS}) \\
C P^{4}(\% \text { of } D M)\end{array}$ \\
\hline Fresca & 15,68 & 5,53 & 26,24 & 4,60 \\
\hline Fresh & & & & \\
\hline Murcha & 12,23 & 2,76 & 32,79 & 4,35 \\
\hline Wilted & & & & \\
\hline $\begin{array}{l}\text { M.SI.T0 } \\
W . W I . T 0\end{array}$ & - & - & 29,76 & 4,43 \\
\hline M.CI.T0 & - & - & 29,65 & 4,24 \\
\hline
\end{tabular}

1 = poder tampão, 2 = carboidrato solúvel, 3 = matéria seca, 4 = proteína bruta.

1 = buffer capacity, 2 = water soluble carbohydrates, 3 = dry matter, 4 = crude protein.

ma. Para permitir circulação de ar, foram feitos dois orifícios de $1 \mathrm{~cm}$ de diâmetro, um na tampa e outro no fundo, protegidos por uma tela para evitar a entrada de insetos. Nesta parte, foram colocados, levemente compactada, de 250-300 g de silagem (peso úmido),devidamente anotados. A parte inferior da unidade, que foi feita de outra garrafa, recebeu 100 $\mathrm{mL}$ de $\mathrm{KOH} 20 \%$. As partes inferior e superior foram encaixadas formando o sistema.

Junto com a avaliação da produção de $\mathrm{CO}_{2}$, para todos os tempos de exposição, as silagens foram amostradas e submetidas a análises químicas (pH, N$\mathrm{NH}_{3}$ como \% do $\mathrm{N}$ total, $\mathrm{MS}, \mathrm{PB}$, cinzas e FDN) e microbiológicas (contagem de leveduras, fungos filamentosos e lactobacilos) para melhor caracterização do processo de deterioração. Para tanto, a quantidade de silagem contida em cada sistema (250-300 g) precisou ser corretamente fracionada, onde cerca de $30 \mathrm{~g}$ foram levados para o laboratório de microbiologia; 75 a $80 \mathrm{~g}$ foram levados à estufa com circulação forçada a $65^{\circ} \mathrm{C}$ por 60 horas para determinação da MS e posteriormente moídas, passando por peneiras com crivos de $1 \mathrm{~mm}$, para determinação da $\mathrm{PB}$, cinzas, FDN (Silva, 1981). Do conteúdo de silagem restante nos sistemas (aproximadamente $160 \mathrm{~g}$ ), era extraído, com prensa hidráulica, e congelado, o suco da silagem, para a determinação do $\mathrm{N}-\mathrm{NH}_{3}$, segundo a metodologia de Preston (1986). Antes do congelamento do extrato da silagem, foram medidos os valores do $\mathrm{pH}$ (potenciômetro).

Para as análises microbiológicas, logo após a amostragem, as silagens foram levadas ao laboratório de microbiologia para a contagem de microrganis- mos nos respectivos meios de cultura. A análise microbiológica das amostras consistiu no preparo de uma diluição prévia, pesando $25 \mathrm{~g}$ de silagem (matéria verde) em $225 \mathrm{~mL}$ de solução salina estéril (8,5 g de $\mathrm{NaCl} /$ litro de água destilada). Após agitação e filtragem, foram retirados $10 \mathrm{~mL}$ do extrato para as diluições em série. A partir dos extratos diluídos, foram realizadas as semeaduras nos meios específicos. As diluições dos extratos variaram de acordo com os tempos de exposição nos sistemas, onde em T0 as diluições dos extratos variaram de $10^{-1}$ a $10^{-4}$; T2 e T4 de $10^{-1}$ a $10^{-5}$; T6 de $10^{-1}$ a $10^{-7}$; e T8 de $10^{-1}$ a $10^{-8}$ (Lanara, 1981).

Na avaliação do desenvolvimento de lactobacilos, foi usada a metodologia de Jonsson (1991). O meio de cultura utilizado foi o Lactobacilli MRS Agar Dehydrated (Difco), sendo que as placas foram incubadas a $35^{\circ} \mathrm{C}$ por três dias. Para as leveduras e bolores, foi usado o Batata Dextrose Agar (BDA), sendo incubadas de 25 a $30^{\circ} \mathrm{C}$ por 3 a 5 dias (Tengerdy et al., 1991). A diferenciação entre leveduras e bolores foi dada pela própria estrutura física das colônias, uma vez que os bolores são colônias multicelulares filamentosas e as leveduras, unicelulares.

O delineamento experimental adotado foi o inteiramente casualizado, com três repetições, utilizandose o esquema de parcelas sub-subdivididas, de forma que o efeito da inoculação foi alocado nas parcelas, a profundidade dos silos nas subparcelas e os tempos de exposição ao ar nas sub-sub parcelas. Os dados referentes à contagem microbiana foram transformados (logaritmo) e as médias comparadas pelo teste de Tukey (5\%). 


\section{Resultados e Discussão}

$\mathrm{Na}$ Tabela 2, encontram-se os valores de $\mathrm{pH}$, nitrogênio amoniacal $\left(\mathrm{N}-\mathrm{NH}_{3}\right)$, dióxido de carbono $\left(\mathrm{CO}_{2}\right)$, bactérias produtoras de ácido lático $(\mathrm{BAL}) \mathrm{e}$ bolores (B) de silagens de capim-elefante emurchecido, com (CI) ou sem (SI) inoculante, durante exposição ao ar.

Os valores de $\mathrm{pH}$ das silagens inoculadas foi menor $(\mathrm{P}<0,05)$ que das silagens controle apenas no $8^{\circ}$ dia de exposição, 4,83 e 5,83 , respectivamente. Deve-se salientar que as diferenças de $\mathrm{pH}$ entre as silagens com e sem inóculo foi pequena desde a abertura do silo até seis dias de aeração. Este fato concorda com os resultados de Weinberg et al. (1993) que expuseram por cinco dias, silagens de gramínea inoculadas com Lactobacillus plantarum e controle, no mesmo sistema PET, encontrando valores de $\mathrm{pH}$ bastante próximos $(4,2$ × 3,9 e 4,2 e 4,0 para as silagens controle e inoculadas antes e depois da exposição, respectivamente).

Para as silagens não tratadas (SI), até quatro dias expostas nos sistemas, não ocorreu grande variação do $\mathrm{pH}$, mas aos seis dias de exposição (T6) houve elevação significativa $(\mathrm{P}<0,05)$ em relação à abertura do silo (T0) e aos dois dias de exposição (T2), porém não diferiu $(\mathrm{P}>0,01)$ das expostas por quatro dias $(\mathrm{T} 4)$. As silagens SI com oito dias de exposição (T8), apresen- taram maior $(\mathrm{P}<0,05)$ valor de $\mathrm{pH}$ que as dos demais tempos nos sistemas. Ashbell et al. (1991), também utilizando o sistema PET para avaliação da deterioração aeróbica de silagens de gramínea por um período de dez dias de exposição, encontraram valores de $\mathrm{pH}$ superiores ao do presente estudo, tanto na abertura dos silos $(5,0)$ como após dez dias de exposição $(8,2)$. Com relação às silagens tratadas, as variações dos valores de $\mathrm{pH}$ não foram consistentes.

Se considerado isoladamente, o valor do $\mathrm{pH}$ pode se tornar um índice de qualidade de silagens de pequena valia. $\mathrm{O} \mathrm{pH}$ usualmente acompanha as mudanças que podem ocorrer no conteúdo de $\mathrm{N}-\mathrm{NH}_{3} \mathrm{e}$ ácidos orgânicos (Silveira, 1988). Pode-se dizer que as silagens em estudo, foram bem conservadas durante o período de armazenamento, pois na abertura dos silos apresentaram valores satisfatórios de $\mathrm{pH}$ e $\mathrm{N}-\mathrm{NH}_{3}(3,88$ × 3,97 e 7,09 x 6,57 N-NH$\%$ do NT, para as inoculadas e controle, respectivamente), conforme os parâmetros citados por Lavezzo (1992).

Pelos teores de nitrogênio amoniacal das silagens inoculadas e controle nos tempos de exposição apresentados (Tabela 2), nota-se que aos seis dias de exposição as silagens inoculadas tiveram maior $(\mathrm{P}<0,01)$ teor de $\mathrm{N}-\mathrm{NH}_{3}$ que as silagens controle e que essa diferença tendeu $(\mathrm{P}>0,05)$ a persistir em $\mathrm{T} 8$. A redução nos teores de nitrogênio amoniacal observada durante o período de exposição, não deve ser

Tabela 2 - Valores de $\mathrm{pH}$, nitrogênio amoniacal $\left(\mathrm{N}-\mathrm{NH}_{3}\right)$, dióxido de carbono $\left(\mathrm{CO}_{2}\right)$, proteína bruta $(\mathrm{PB})$ e bolores $(\mathrm{B})$ de silagens de capim-elefante emurchecido, com $(\mathrm{Cl})$ ou sem $(\mathrm{SI})$ inoculante, durante exposição ao ar

Table 2 - $\mathrm{pH}$ values, ammonia nitrogen $\left(\mathrm{NH}_{3}-\mathrm{N}\right)$, carbon dioxide $\left(\mathrm{CO}_{2}\right)$, crude protein $(\mathrm{CP})$, and mold (M) of elephantgrass wilted silages, inoculated (WI) and not inoculated (WO), during aerobic exposure

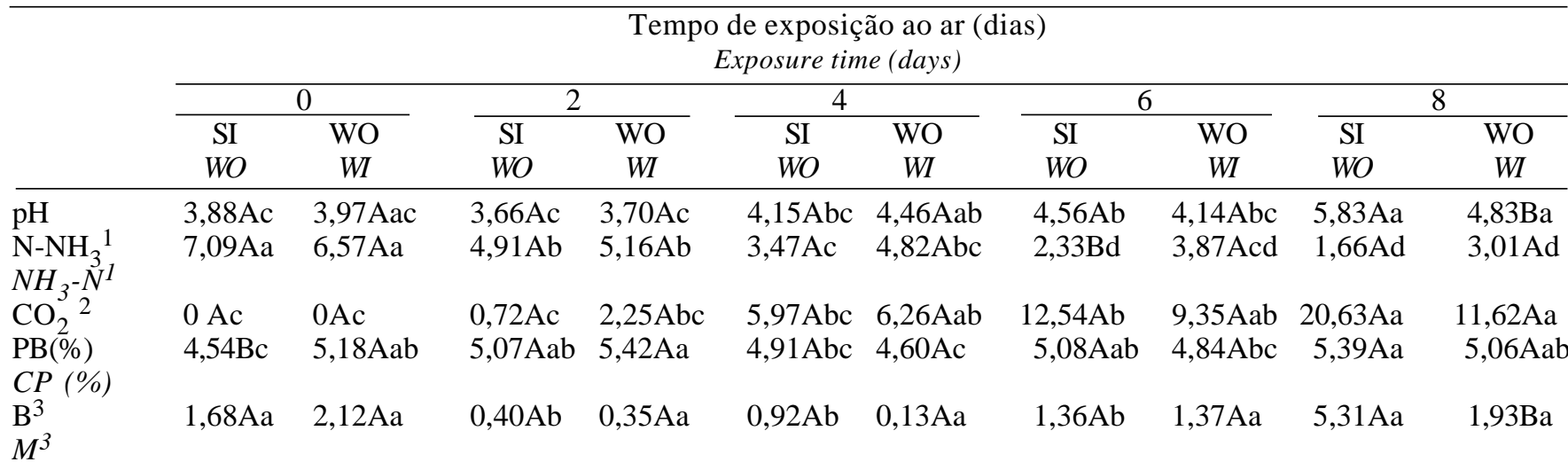

Médias na mesma linha com letras distintas (maiúsculas para o efeito de inoculação no mesmo tempo de exposição, minúsculas para o mesmo tratamento ao longo do tempo de exposição), diferem pelo teste de Tukey $(P<0,05)$.

$1=$ porcentagem do nitrogênio total; $2=\mathrm{g} \mathrm{CO}_{2} / \mathrm{kg} \mathrm{MS} ; 3=$ Unidades Formadoras de Colônias.

Averages within a row, followed by different letter (capital letter to inoculation effect for the same period of exposure, small letter for same treatment on different days), differ by Tukey test $(P<0.05)$.

$1=$ percent of total nitrogen; $2=g \mathrm{CO}_{2} / D M \mathrm{~kg} ; 3=$ Colony Forming Unit.

\section{R. Bras. Zootec., v.31, n.6, p.2176-2185, 2002}


atribuída à volatilização, pois mesmo após oito dias de aeração os valores de $\mathrm{pH}$ não foram superiores a seis. Para isso, sugere-se que houve uma imobilização de $\mathrm{N}$ pelos fungos miceliares (em suas hifas), como nitrogênio orgânico, após a abertura dos silos. Uma vez que a determinação do $\mathrm{N}-\mathrm{NH}_{3}$ foi feita no suco da silagem, essa imobilização de $\mathrm{N}$ pelos fungos filamentosos poderia impedir a sua passagem para o líquido, tornando-o cada vez mais pobre proporcionalmente ao crescimento das hifas, distribuídas uniformemente no sistema PET. Os maiores teores de $\mathrm{N}-\mathrm{NH}_{3}$ determinados nas silagens inoculados podem reforçar essa hipótese, pois também apresentaram menor desenvolvimento de fungos miceliares que as não inoculadas.

Registra-se que não houve diferença significativa entre as produções de $\mathrm{CO}_{2}$ das silagens inoculadas e controle durante o armazenamento aeróbico (Tabela 2). Cabe destacar que mesmo não apresentando diferenças estatisticamente significativas $(\mathrm{P}>0,05)$, ao final de oito dias de aeração pode-se detectar tendência de produção de $\mathrm{CO}_{2}$ mais baixa para as silagens inoculadas. Para os tempos de exposição, verificouse aumento $(\mathrm{P}<0,01)$ gradativo da produção de $\mathrm{CO}_{2}$, de modo que as silagens sem inóculo, depois de dois dias de exposição, passaram a apresentar elevação da produção de $\mathrm{CO}_{2}$ mais acentuada que as silagens inoculadas. Com relação à proteína bruta $(\mathrm{PB})$ das silagens, não foi registrado efeito significativo tanto para a inoculação $(4,99$ e 5,02 \% PB, para as silagens SI e CI, respectivamente) quanto para as profundidades do silo $(5,09 ; 4,97$ e 4,97 \% PB para as silagens das camadas superficial (P1), intermediária (P2) e funda (P3), na mesma ordem).

Na deterioração aeróbica de silagens de gramínea, as primeiras substâncias utilizadas como substrato pelos microrganismos são os extrativos não nitrogenados como os carboidratos solúveis e ácidos orgânicos, o que leva a aumentos correspondentes nos teores de fibra, proteína bruta e cinzas (Honig \& Woolford, 1980). O aumento $(\mathrm{P}<0,05)$ nos teores de PB (Tabela 2) tanto das silagens inoculadas quanto das controle, pode ser atribuído ao próprio processo de deterioração da silagem. Os maiores $(\mathrm{P}<0,01)$ teores de proteína bruta registrados para as silagens inoculadas em relação às controle, na abertura dos silos, supõe-se que seja, em parte, atribuídos à conversão de algum nitrato, presente no capim ensilado, em proteína microbiana (Tabela 2).

Em geral, os bolores são aeróbios, exigem $\mathrm{pH}$ ótimo para crescimento entre 5-6 e a seqüência normal de reprodução é: esporo $\rightarrow$ esporo com tubo germinativo $\rightarrow$ hifa $\rightarrow$ micélio (conjunto de hifas) $\rightarrow$ órgãos de frutificação $\rightarrow$ novos esporos. Para que o fungo produza seus órgãos de frutificação, pode levar de 3 a 14 dias, variando em função da espécie (Ruiz, 1992).

No presente trabalho, pode-se inferir que a contagem de fungos filamentosos na abertura dos silos (T0), dada a ausência de $\mathrm{O}_{2}$, foi de esporos (Tabela 2). A queda na contagem das unidades formadoras de colônias (UFC) após a abertura dos silos até seis dias de exposição pode ser atribuída ao próprio metabolismo intenso desses microrganismos no processo de desenvolvimento de seus órgãos de frutificação. Durante este período, ocorreram importantes alterações nos valores de $\mathrm{pH}$, provocadas principalmente pelas enzimas das leveduras e dos fungos filamentosos. Já aos oito dias de exposição, a contagem de bolores voltou a aumentar $(\mathrm{P}<0,05)$ devido ao lançamento de novos esporos, apresentando maior atividade fúngica.

Entre as silagens que não receberam o inoculante (Tabela 2), detectou-se maior $(\mathrm{P}<0,05)$ contagem de bolores após oito dias de exposição em relação aos tempos anteriores, o que não foi registrado para as silagens inoculadas. Tal fato pode ser alicerçado nas variações do $\mathrm{pH}$, onde as silagens inoculadas apresentaram valores médios inferiores às controle $(\mathrm{P}>0,01)$. A interação profundidade $\mathrm{x}$ tempo de exposição não foi significativa. Os resultados encontrados neste trabalho, referentes aos bolores, foram inferiores aos obtidos por Ashbell et al.(1991), que trabalharam com silagens de capim, utilizando o mesmo sistema PET. Weinberg et al.(1993), trabalhando com o sistema PET, silagem de trigo e utilizando inoculante microbiano, não encontraram bolores, mesmo após 5 dias de aeração.

Os coeficientes de variação registrados para $\mathrm{pH}$, $\mathrm{N}-\mathrm{NH}_{3}, \mathrm{CO}_{2}$, proteína bruta e bolores, para o efeito de inoculação (parcela) e tempo de exposição aeróbica (sub parcelas) estão apontados na Tabela 3. Os elevados valores encontrados, particularmente para as produções de $\mathrm{CO}_{2}$, podem ser justificados pela pequena capacidade dos sistemas PET de avaliação de estabilidade aeróbica (1 L) e pelas diferentes quantidades de silagens colocadas nesses sistemas (variavam de 250 a $300 \mathrm{~g}$ ). De modo que quanto menor a quantidade de material avaliado, maiores são as variações, conseqüentemente, menores as probabilidades de se detectar diferenças estatisticamente significativas. Uma das formas de minimizar essas

R. Bras. Zootec., v.31, n.6, p.2176-2185, 2002 
Tabela 3 - Valores dos coeficientes de variação (CV) registrados para $\mathrm{pH}$, nitrogênio amoniacal $(\mathrm{N}$ $\left.\mathrm{NH}_{3}\right)$, dióxido de carbono $\left(\mathrm{CO}_{2}\right)$, proteína bruta (PB) e bolores (B) para o efeito de inoculação (parcela) e tempo de exposição (sub parcela) de silagens de capim-elefante emurchecido

Table 3 - Coefficient of variation (CV) for $\mathrm{pH}$ values, ammonia nitrogen $\left(\mathrm{NH}_{3}-\mathrm{N}\right)$, carbon dioxide $\left(\mathrm{CO}_{2}\right)$, crude protein $(C P)$ and mold $(M)$ to inoculation effect (parcel) and exposure time (sub parcel) of wilted grass silages

\begin{tabular}{lccccc}
\hline $\mathrm{CV}(\%)$ & \multicolumn{5}{c}{ Variáveis } \\
& $\mathrm{pH}$ & $\mathrm{N}^{-\mathrm{NH}_{3}}$ & $\mathrm{CO}_{2}$ & $\mathrm{~PB}$ & Bolores \\
& $\mathrm{pH}$ & $\mathrm{NH}_{3}-\mathrm{N}$ & $\mathrm{CO}_{2}$ & $\mathrm{CP}$ & Mould \\
\cline { 2 - 6 } & 23,46 & 57,95 & 229,32 & 12,25 & 125,92 \\
Parcela & & & & & \\
$\begin{array}{l}\text { Plot } \\
\text { Subparcela } \\
\text { Splitplot }\end{array}$ & 9,61 & 25,58 & 188,07 & 4,49 & 88,01 \\
& & & & & \\
\hline
\end{tabular}

variações, seria a padronização da quantidade exata de silagem colocada dentro dos sistemas, evitando-se assim, diferenças no grau de compactação das silagens e, conseqüentemente, na circulação de oxigênio pelo material; e, a outra, seria a utilização de sistemas de maior capacidade (galões de 5L).

O mecanismo de deterioração aeróbica é complexo e depende de uma interação de fatores químicos, físicos e microbiológicos (Sanderson, 1993). Os lactobacilos podem crescer na presença de oxigênio, mas não podem utilizá-lo (Stainer et al.; citados por Williams et al., 1994). Dessa forma, seus únicos métodos de produção de ATP são fermentativos, produzindo principalmente o ácido lático. O estímulo para o crescimento dos lactobacilos provavelmente não é o oxigênio em si, mas uma conseqüência da sua presença (Williams et al., 1994). Altas concentrações de $\mathrm{CO}_{2}$ limitam o crescimento de leveduras e podem tanto inibir como promover o crescimento de lactobacilos (Muck et al.,1992). Assim sendo, os resultados encontrados no presente estudo revelam que o $\mathrm{CO}_{2}$ proporcionou aumento $(\mathrm{P}<0,05)$ da contagem de lactobacilos nos dois últimos tempos de exposição aeróbica (Tabela 4).

Por outro lado, tanto a inoculação $(6,73 \times 6,43 \mathrm{log}$ UFC/g MS, para as silagens SI e CI, respectivamente) quanto as profundidades do silo $(6,81 ; 6,79$ e 6,23 log UFC/g MS, para P1;P2 e P3, na mesma ordem) não apresentaram diferenças $(\mathrm{P}>0,05)$ nas contagens de lactobacilos. As interações entre inoculação x tempo e profundidade $\mathrm{x}$ tempo também não foram significativas.

Os fungos, particularmente as leveduras, são os microrganismos mais freqüentes associados à deterioração da silagem (Lindgren et al.,1985; McDonald et al.,1991). Vale lembrar que somente a contagem de leveduras não explica as diferenças na estabilidade das silagens (Henderson et al., 1979). Daniel et al., citados por Honig \& Woolford (1980), comentaram que silagens com mais de $10^{5} \mathrm{UFC} / \mathrm{g}$ MS parecem ser mais propensas à deterioração, porém isso não pode ser considerado como um fator decisivo uma vez que silagens com menores populações de leveduras também podem deteriorar rapidamente (Henderson, 1993).

As populações de leveduras em vários tipos de silagens podem aumentar de menos $10^{2}$ a $10^{12} \mathrm{UFC} / \mathrm{g}$ MS dentro de três dias (Woolford, 1990). No presente estudo, houve diferença $(\mathrm{P}<0,01)$ na presença das leveduras ao longo dos tempos de exposição. A queda significativa da contagem de leveduras após dois dias de exposição ao ar pode ser atribuída ao "lag" de adaptação da nova condição de aerobiose, que depois começa a subir gradativamente até oito dias de exposição. Os resultados encontrados antes (T0) e depois da aeração (T2-T8) foram inferiores aos encontrados por Ashbell et al. (1991) e Weinberg et

Tabela 4 - Presença de lactobacilos e leveduras nas silagens de capim-elefante, ao longo dos tempos de exposição aeróbica

Table 4 - Lactobacilli and yeast presence on elephantgrass silages during aerobic exposure

\begin{tabular}{lcc}
\hline $\begin{array}{l}\text { Tempos de exposição (dias) } \\
\text { Exposure time (days) }\end{array}$ & $\begin{array}{c}\text { Lactobacilos (log UFC/g silagem) } \\
\text { Lactobacili (log CFU/g silage) }\end{array}$ & $\begin{array}{c}\text { Leveduras (log UFC/g MS) } \\
\text { Yeast (log CFU/g DM) }\end{array}$ \\
\hline 0 & $5,97 \mathrm{C}$ & $5,94 \mathrm{~B}$ \\
2 & $6,06 \mathrm{C}$ & $5,47 \mathrm{C}$ \\
4 & $6,55 \mathrm{~B}$ & $6,33 \mathrm{~B}$ \\
6 & $6,97 \mathrm{AB}$ & $6,96 \mathrm{~A}$ \\
8 & $7,32 \mathrm{~A}$ & $7,30 \mathrm{~A}$ \\
$\mathrm{CV}(\%)$ & 7,05 & 5,91 \\
\hline
\end{tabular}

Médias seguidas de letras distintas diferem pelo teste de Tukey $(\mathrm{P}<0,01)$.

Means followed by different letter differ by Tukey test $(P<0.01)$.

R. Bras. Zootec., v.31, n.6, p.2176-2185, 2002 
al. (1993), que trabalharam com o mesmo sistema PET, mas semelhantes aos encontrados por Williams et al. (1994), que avaliaram o efeito da concentração de oxigênio sobre silagens de capim.

Os valores de $\mathrm{pH}$ (Tabela 5) das silagens, nas camadas superficiais $(\mathrm{P} 1=0-35 \mathrm{~cm})$, não diferiram $(\mathrm{P}>0,01)$ entre a abertura do silo e aos dois dias de exposição (T2), porém a queda do pH em T2 foi significativa $(\mathrm{P}<0,01)$ em relação aos outros tempos de exposição. A partir daí, o pH foi subindo lentamente, pois os valores detectados aos quatro dias de exposição ao ar não foram significativamente diferentes em relação ao sexto dia, porém no oitavo dia se mostraram superiores $(\mathrm{P}<0,01)$ quando comparados aos demais. Nas camadas intermediárias $(35-65 \mathrm{~cm})$, apenas aos 8 dias de exposição o pH apresentou elevação estatisticamente significativa $(\mathrm{P}<0,05)$; já nas camadas profundas $(\mathrm{P} 2=65-97 \mathrm{~cm})$, as variações nos valores de $\mathrm{pH}$ foram menos acentuadas. Esse fato pode ser atribuído à transformação do ácido pelas leveduras ou bactérias aeróbicas nas camadas mais superficiais, sujeitas a maior presença de oxigênio.

Para a produção de $\mathrm{CO}_{2}(\mathrm{~g} / \mathrm{kg} \mathrm{MS})$, não foi detectada diferença $(\mathrm{P}>0,05)$ entre as camadas do silo até o quarto dia de exposição (Tabela 5). Desde a abertura dos silos, as silagens de P1 apresentaram maiores produções; porém, a partir de seis dias de exposição as diferenças passaram a ser significativas em relação às das camadas inferiores (P2 e P3) e, aos oito dias, as silagens da camada intermediária (P2) não diferiram da camada superficial (P1), mas foram superiores $(\mathrm{P}<0,05)$ às do fundo. É preciso deixar claro que o efeito da profundidade se dá no período em que o silo está fechado (período de anaerobiose), sendo que na camada superficial a compactação se mostra menos eficiente, permitindo maior crescimento microbiano. A partir da remoção da silagem e colocação no sistema PET, é conferido semelhante grau de compactação à silagem. Lindgren et al. (1985), Ashbell \& Lisker (1988) e Ashbell \& Weinberg (1991), mesmo trabalhando com silos tipo "bunker", encontraram resultados semelhantes.

A inoculação não exerceu influência $(\mathrm{P}>0,05)$ sobre o desenvolvimento de leveduras $(6,47 \times 6,33 \mathrm{log}$ UFC/g MS para as silagens SI e CI, respectivamente), assim como a interação entre inóculo $\mathrm{x}$ tempo de exposição não foi significativa. Já para as profundidades dos silos, notou-se que as silagens das camadas inferiores do silo (P3) (6,00 log UFC/g MS) apresentaram menor $(\mathrm{P}<0,01)$ contagem que as das camadas intermediárias (P2) e superficiais (P1) (6,77 e 6,42 $\log$ UFC/g MS, respectivamente), que não diferiram

Tabela 5 - Valores de $\mathrm{pH}$ e dióxido de carbono $\left(\mathrm{g} \mathrm{CO}_{2} / \mathrm{kg} \mathrm{MS}\right.$ ) das silagens de capim- elefante, nas três profundidades $(\mathrm{P})$ dos silos, nos diferentes tempos de exposição aeróbica

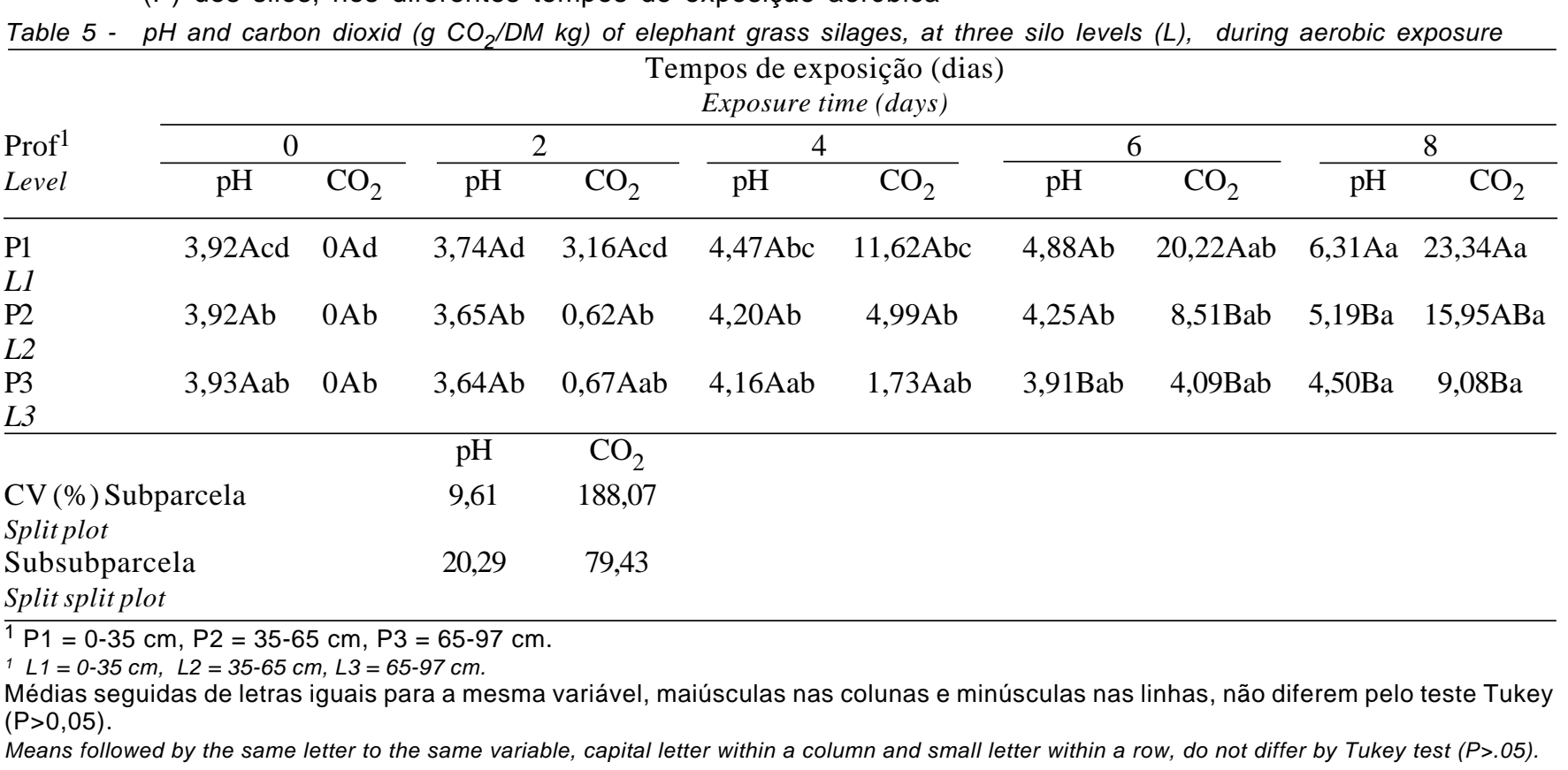

R. Bras. Zootec., v.31, n.6, p.2176-2185, 2002 
entre si. Segundo Pahlow \& Zimmer, citados por McDonald et al. (1991), o uso de inoculante microbiano poderia fornecer algumas medidas de proteção contra a ação das leveduras, via produção de ácidos. Porém, na camada superficial, onde a concentração de oxigênio é alta, a inoculação não inibirá as leveduras, permitindo que oxidem os ácidos, proporcionando, assim, a elevação do $\mathrm{pH}$.

$\mathrm{O}$ crescimento das leveduras mostrou-se mais intenso na camada superficial durante a exposição ao ar (Tabela 6). No quarto dia de exposição, seu desenvolvimento começou a se diferenciar nas profundidades e foi se acentuando no sexto e oitavo dias. Este fato pode ser confirmado pelo aumento da produção de $\mathrm{CO}_{2}$ e a elevação dos valores do $\mathrm{pH}$ (Tabela 5).

Os teores de fibra em detergente neutro (FDN) e cinzas não apresentaram alterações significativas (P>0,05) para efeito de inóculo $(76,75 \times 76,11 \%$ e
$8,64 \times 8,68 \%$, respectivamente, para FDN e cinzas das silagens com inóculo e controle) e profundidade $(76,56$ x 76,58 x 76,0\% e 8,61 x 8,68 x 8,65\%, para FDN e cinzas das silagens de P1, P2 e P3, na mesma ordem). Nos tempos de aeração, as silagens também não mostraram mudanças $(\mathrm{P}>0,05)$ nos teores de cinzas e FDN, e isto permite supor que oito dias de exposição aeróbica não foram suficientes para iniciar a decomposição dos carboidratos estruturais. As interações inóculo x tempo de exposição e profundidade $\mathrm{x}$ tempo, tanto para FDN como para cinzas, não foram estatisticamente significativas.

Para maior dimensão do estudo da deterioração de silagens, uma vez que esta é governada por agentes microbianos, sugere-se novos trabalhos no campo de estudo das micotoxinas, já que grande parte dos problemas reprodutivos, principalmente no rebanho leiteiro nacional, é atribuído a micotoxicoses.

Tabela 6 - Desenvolvimento de leveduras (log UFC/g silagem) nas silagens de capim elefante, nas três profundidades $(\mathrm{P})$ do silo, ao longo dos tempos de exposição aeróbica

Table 6 - Development of yeast (logCFU/silage g) in elephantgrass silages, at three silo levels (L), during aerobic exposure

\begin{tabular}{|c|c|c|c|c|c|}
\hline \multirow{2}{*}{$\begin{array}{l}\text { Profundidades } \\
\text { Levels }^{1}\end{array}$} & \multicolumn{5}{|c|}{$\begin{array}{c}\text { Tempos de exposição (dias) } \\
\text { Exposure time (days) }\end{array}$} \\
\hline & 0 & 2 & 4 & 6 & 8 \\
\hline $\mathrm{P} 1$ & & & & & \\
\hline $\begin{array}{l}\mathrm{L} 1 \\
\mathrm{P} 2\end{array}$ & $5,97 \mathrm{Ac}$ & $5,52 \mathrm{Ac}$ & $6,91 \mathrm{Ab}$ & $7,65 \mathrm{Ab}$ & 7,80Aa \\
\hline $\begin{array}{l}\mathrm{L} 2 \\
\mathrm{P} 3\end{array}$ & 5,93Acd & $5,55 \mathrm{Ad}$ & $6,38 \mathrm{Abc}$ & $6,85 \mathrm{Bab}$ & 7,39Aa \\
\hline $\mathrm{L} 3$ & $5,92 \mathrm{Abc}$ & $5,34 \mathrm{Ac}$ & $5,68 \mathrm{Bbc}$ & $6,38 \mathrm{Bab}$ & $6,69 \mathrm{Ba}$ \\
\hline $\begin{array}{l}\text { CV (\%) Subparcela } \\
\text { Splitplot }\end{array}$ & & 8,13 & & & \\
\hline $\begin{array}{l}\text { Subsubparcela } \\
\text { Split split plot }\end{array}$ & & 7,22 & & & \\
\hline
\end{tabular}

\section{Conclusões}

A inoculação dos microrganismos eficazes proporcionou o mesmo comportamento de deterioração que o das silagens controle, no início do processo. Porém, a partir de seis dias de exposição, as silagens inoculadas passaram a apresentar menor velocidade de deterioração.

Os dados obtidos nas diferentes profundidades do silo experimental mostraram que a camada superficial tem maior velocidade de deterioração durante a exposição ao ar, que aparece como reflexo do padrão de fermentação durante a anaerobiose. 


\section{Literatura Citada}

ASHBELL, G.; LISKER, N. Aerobic deterioration in maize silage stored in a bunker silos under farm conditions in a subtropical climate. Journal of Food and Agriculture Science, v.45, n.4, p.307-315, 1988.

AHSBELL, G.; WEIBERG, Z.G.; AZRIELI, A. A simple system to study the aerobic determination of silages. Canadian Agricultural Engineering, v.34, p.171-175, 1991.

AHSBELL, G.; WEINBERG, Z.G. Top silage losses in horizontal silos. Canadian Agricultural Engineering, v.33, p.391393, 1991.

BUGHARDI, S.R., GOODRICH, R.D., MEIKE, K.C. Evaluation of corn silage treated with microbial additives. Journal of Animal Science, v.50, n.4, p.729-36, 1980.

HENDERSON, A.R.; ENART, M.J.; ROBERTSON, G.M. Studies on the aerobic stability of commercial silages. Journal of Food and Agriculture Science, v.30, n.3, p.223-228, 1979.

HENDERSON, N. Silages additives. Animal Feed Science and Technology, v. 45, p. 35-56, 1993.

HIGA, T. O meio ambiente do ponto de vista do mundo microscópico. In: Forum Global das Organizações Não-Governamentais. Rio de Janeiro: Fundação Mokiti Okada, 1992. 11p.

HIGA, T.; PARR, J.F. Beneficial and effective microorganisms for a sustainable agriculture and environment. Atami: International Nature Farming Research Center, 1994. 16p.

HONIG,H.; WOOLFORD,M.K. Changes in silage exposure to air. In: FORAGE CONSERVATION IN THE 80's, 1979, Brighton. Proceeding... Oxford: British Grassland Society, 1980. p.76-87.

JOHNSON, L.J.; McCLURE, K.E.; DEHORITY, B.A. Corn plant maturity. Journal of Animal Science, v.25, p.617623, 1966.

JONSSON, A. Growth of Clostridium tyrobutiricum during fermentation and aerobic deterioration of grass silage. Journal of the Science of Food and Agriculture, v.54, n.4, p.557568, 1991.

LANARA. Métodos analíticos oficiais para controle de produtos de origem animal e seus ingredientes. I- Métodos Microbiológicos. Ministério da Agricultura. BrasíliaDF, 1981.

LAVEZZO, W. Ensilagem do capim-elefante. In: SIMPÓSIO SOBRE MANEJO DE PASTAGEM, 10., 1992, Piracicaba. Anais...Piracicaba: Fundação de Estudos Agrários "Luiz de Queiroz", 1992. p.169-275.

LINDGREN, S.; PETTERSON, K.; KASPRSON, A. et al. Microbial dynamics during aerobic deterioration of silages. Journal of the Science of Food and Agriculture, v.36, p.765-774, 1985.

McDONALD,P.; HENDERSON, A.R.; HERON, S.J.E. The biochemistry of silage. New York: Chalcombe Publications, 1991. 339p.

MUCK, R.E. Dry matter level effects on alfafa silage quality. II. Fermentation products and starch hydrolysis. Transaction of ASAE, v.33, n.2, p.373-381, 1990.

MUCK, R.E.; SPOELTRA, S.F.; WIKESELAAR, P.G. Effects of carbon dioxide on fermatation and aerobic stability of maize silage. Journal of the Science of Food and Agriculture, v.59, p.405-412, 1992.

PITT, R.E; SHAVER, R.D. Processes in preservation of hay and silage. In: DAIRY FEEDING SYSTEMS SIMPOSIUM,
Harrisburg, Pennsilvania, 1990. Proceedings... Harrisburg: NARES, 1990. p.72-87.

PLAYNE, M.J.; McDONALD, P. The buffering constituents of herbage and silage. Journal of the Science of Food and Agriculture, v.17, p.264-268, 1966.

PRESTON, T.R. Better Utilization of crop residues and byproducts in animal feeding: research guidelines - 2. A practical manual for research workers. Rome: FAO, 1986. $154 \mathrm{p}$.

RUIZ, R.L. Fungos e seu interesse em zootecnia. In: Microbiologia zootécnica. São Paulo: Roca, 1992. p.37-50.

RUIZ, R.L.; MUNARI, D.P. Microbiologia da silagem. In: Microbiologia zootécnica. São Paulo: Roca, 1992. p.97-122.

SANDERSON, M. Aerobic stability and in vitro digestibility of microbially inoculated corn and sorghum silages. Journal of Animal Science, v.71, p.505-514, 1993.

SHARP, R.; HOPPER P.G.; ARMSTRONG, D.G. The digestion of grass silages produced using inoculants of lactic acid bacteria. Grass and Forage Science, v.49, p.42-53, 1994.

SILVA, D.J. Análise de alimentos: métodos químicos e biológicos. Viçosa, MG: Universidade Federal de Viçosa, 1981. 165p.

SILVEIRA, A.C. Produção e utilização de silagens. In: SEMANA DE ZOOTECNIA, 12., 1988, Pirassununga. Anais... Campinas: Fundação Cargil, 1988. p.119-134.

SPOELSTRA, S.F. Influences of air on silage preservation and aerobic stability. In: GENERAL MEETING OF THE EUROPEAN GRASSLAND FEDERATION, 15., 1994, Wageningem. Proceedings... Wageningem: 1994. p.566-577.

TENGERDY,R.P., WEINBERG,Z.G., SZAKACS,G., et al. Ensiling alfalfa with additives of lactic acid bacteria and enzymes. Journal of the Science of Food and Agriculture, v.55, n.2, p.215-228, 1991.

TOKESHI,H.; LIMA,M.A.T.; JORGE,M.J.A. Efeitos dos microrganismos eficazes e adubação verde na produtividade do solo no Brasil. In: Experimentos sobre o uso dos microrganismos eficazes (E.M.) no Brasil - Trabalhos apresentados na terceira Conferência Internacional de Agricultura Natural Messiânica. Santa Bárbara, Califórnia, 1993. São Paulo: Fundação Mokiti Okada, 1994. p.27-43.

VILELA, D. Utilização do capim-elefante na forma de forragem conservada. In: CAPIM-ELEFANTE: PRODUÇÃO E UTILIZAÇÃO. Coronel Pacheco, MG, 1994. Anais... Coronel Pacheco: Centro Nacional de Pesquisa de Gado de Leite, 1994. p.117-164.

WEINBERG, Z.G. ASHBELL, G.; HEN, Y. et al. Ensiling peas, ryegrass and wheat with additives of lactic acid bacteria (LAB) and cell wall degrading enzymes. Grass and Forage Science, v.48, p.70-78, 1993.

WILLIAMS, A.G.; LOWE J. F.; REES D.V. The effect of oxygen concentration on changes in microbial population, temperature and dry-matter content grass silage. Grass and Forage Science, v.49, p.183-191, 1994.

WOOLFORD, M.K. The detrimental effects of air on silage- A review. Journal of Applied Bacteriology, v.68, p.101-116, 1990.

R. Bras. Zootec., v.31, n.6, p.2176-2185, 2002

Recebido em: 15/10/01 Aceito em: 04/04/02 